Check for updates

Cite this: RSC Adv., 2017, 7, 22692

Received 5th February 2017

Accepted 19th April 2017

DOI: $10.1039 / \mathrm{c} 7 \mathrm{ra01469d}$

rsc.li/rsc-advances

\section{Three sandwich-type zinc(II)-lanthanide(III) clusters: structures, luminescence and magnetic properties $\dagger$}

\author{
Xue-Qin Song, (D) *a Pan-Pan Liu, ${ }^{\text {a }}$ Cai-yun Wang, ${ }^{a}$ Yuan-An Liu, ${ }^{a}$ Wei-Sheng Liu (D) ${ }^{b}$ \\ and Mo Zhang a
}

Three new sandwich-type hexanuclear $Z n^{\prime \prime}-L^{\prime \prime \prime}$ clusters based on a methoxy substituted salicylamide Salen-like ligand and o-vanilline, $\left[\mathrm{Zn}_{2} \mathrm{Ln}_{4}(\mathrm{HL})_{4}(\mathrm{O} \text {-vanilline })_{2}(\mathrm{OH})_{4}\left(\mathrm{CH}_{3} \mathrm{OH}\right)_{2}\right] \cdot 2 \mathrm{NO}_{3} \cdot 5 \mathrm{CH}_{3} \mathrm{OH}(\mathrm{Ln}=\mathrm{Eu}, \mathrm{Tb}$ and Dy, $\mathrm{H}_{3} \mathrm{~L}=$ 1-(2-hydroxy-4-methoxy-benzamido)-2-(2-hydroxy-3-methoxy-benzylideneamino)ethane) were synthesised. Single-crystal structure analyses reveal that these $Z n^{\prime \prime}-L n^{\prime \prime \prime}$ clusters display a hydroxyl bridged tetranuclear $\mathrm{Ln}_{4}^{\mathrm{III}}$ core sandwiched in an environment of two $\mathrm{Zn}^{\prime \prime}$ ions, four doubly deprotonated $\mathrm{HL}^{2-}$ and two singly deprotonated $\mathrm{o}$-vanilline. Photophysical determinations indicate that the $\mathrm{Zn}^{\prime \prime}-E u^{\text {III }}$ cluster shows mixed emissions both originating from ligands and $\mathrm{Eu}^{\text {III }}$ ions, and the other two only display ligand-centered emission in visible region. The magnetic studies reveal that the $\mathrm{Zn}^{\prime \prime}-$ Dy ${ }^{\text {III }}$ cluster displays rare ferromagnetic behavior with slow magnetic relaxation behavior at zero field.

\section{Introduction}

High-nuclearity heterometallic clusters containing $\mathrm{Zn}^{\mathrm{II}}-\mathrm{Ln}^{\mathrm{III}}$ metal ions have blossomed into a promising topic of modern coordination chemistry and attracted increasing attention primarily because of their interesting magnetic and photophysical properties since the first $\mathrm{Zn}^{\mathrm{II}}-\mathrm{Eu}^{\mathrm{III}} / \mathrm{Sm}^{\mathrm{III}}$ heterometallic clusters were reported in 1995 by Brennan et al. ${ }^{\mathbf{1}}$ This is attributed to: (a) magnetic behaviour that can easily be explained due to the diamagnetic character of the $\mathrm{Zn}^{\text {II }}$ ion, and (b) $\mathrm{Ln}^{\mathrm{III}}$ ions are desired luminescent and magnetic species because of their characteristic 4 f electronic configuration. The magnetic properties of $\mathrm{Zn}^{\mathrm{II}}-\mathrm{Ln}^{\mathrm{III}}$ heterometallic compounds mainly arise from the intrinsic large spin ground state and the strong uniaxial magnetic anisotropy of some $\mathrm{Ln}^{\mathrm{III}}$ ions. It is expected that the incorporation of $\mathrm{Zn}^{\mathrm{II}}$ and $\mathrm{Ln}^{\mathrm{III}}$ ions into one

${ }^{a}$ School of Chemical and Biological Engineering, Lanzhou Jiaotong University, Lanzhou, China. E-mail: songxq@mail.lzjtu.cn; Fax: +86-931-4938755; Tel: +86931-4938755

${ }^{b}$ Lanzhou University, Key Laboratory of Nonferrous Metals Chemistry and Resources Utilization of Gansu Province, State Key Laboratory of Applied Organic Chemistry, College of Chemistry and Chemical Engineering, Lanzhou, China. E-mail: liuws@ lzu.edu.cn; Fax: +86-931-8915151; Tel: +86-931-8915151

$\dagger$ Electronic supplementary information (ESI) available: A brief statement in CIF, figures of TGA curves (Fig. S1), figures of PXRD curves (Fig. S2), coordination polyhedron of $\mathrm{Dy}^{\mathrm{III}}$ in $\mathrm{Zn}_{2}^{\mathrm{II}} \mathrm{Dy}_{4}^{\mathrm{III}}$ (Fig. S3), excitation spectra of $\mathrm{Zn}_{2}^{\mathrm{II}} \mathrm{Eu}_{4}^{\mathrm{III}}$ (Fig. S4), emission decay curves of $\mathrm{Zn}_{2}{ }_{2} \mathrm{Eu}^{\mathrm{III}}{ }_{4}, \mathrm{Zn}^{\mathrm{II}}{ }_{2} \mathrm{Eu}^{\mathrm{III}}{ }_{4}$, and $\mathrm{Zn}_{2}{ }_{2} \mathrm{Dy}^{\mathrm{III}}{ }_{4}$ (Fig. S5-S7), emission spectra of different wavelength excitation (Fig. S8-S10). A summary of the relevant crystallographic data and the final refinement details are given in Table S1, important bond lengths are listed in Table S2. CCDC 482428-1482430. For ESI and crystallographic data in CIF or other electronic format see DOI: 10.1039/c7ra01469d coordination system may not only enhance the structural diversity, but also integrate the optical and magnetic properties of $\mathrm{Ln}^{\text {III }}$ ions which can offer multifunctional properties. ${ }^{2-7}$ To our best knowledge, high-nuclearity $\mathrm{Zn}^{\mathrm{II}}-\mathrm{Ln}^{\mathrm{III}}$ coordination clusters are still scarce because their design and controllable synthesis represent a formidable challenge. Consequently, only a few nanosized $\mathrm{Zn}^{\mathrm{II}}-\mathrm{Ln}^{\mathrm{III}}$ clusters of varying nuclearities range from kite-like $\operatorname{Ln}_{3} Z n,{ }^{2}$ square-shaped $\operatorname{Ln}_{2} Z_{2},{ }^{3}$ cyclic $Z_{2} \operatorname{Ln}_{2},{ }^{4}$ cubane-like $\operatorname{Ln}_{2} \mathrm{Zn}_{2},{ }^{5}$ drum-like $\mathrm{Ln}_{4} \mathrm{Zn}_{8}$ (ref. 6) and triangular ring-like $\operatorname{Ln}_{24} \mathrm{Zn}_{6}$ (ref. 7) have been reported. Due to the strong easy-axis type magnetic anisotropy and larger $J(L+S)$ value originating from lanthanide ions, ${ }^{8}$ the magnetic exploration for $\mathrm{Ln}^{\text {III }}$-based compounds, especially for single-molecule magnets (SMMs), have stimulated a wide range of research interests. Among which, Dy ${ }^{\mathrm{III}}$ ions are the most appealing mainly because they have an inherent strong spin-orbital coupling effect and very large magnetic anisotropy of the ${ }^{6} \mathrm{H}_{15 / 2}$ ground state. It is well known that the coordination environment, the local ligand field and the magnetic interaction strength between metal ions can have impact on SMM behavior of Dy ${ }^{\mathrm{III}}$ containing systems. Undoubtedly, further exploration of ${ }^{\text {DyII }}{ }^{\text {containing SMMs }}$ deserves attention not only for better SMMs but also for deciphering the relaxation dynamics and mechanisms. Although several $\mathrm{Cu}^{\mathrm{II}}-\mathrm{Dy}{ }^{\mathrm{III}}$ clusters displaying ferromagnetic behavior with slow magnetization relaxation systems have been reported, ${ }^{9}$ it is rare that ferromagnetic interaction with slow magnetic relaxation exists in $\mathrm{Zn}^{\mathrm{II}}-\mathrm{Dy}{ }^{\mathrm{III}}$ heterometallic clusters.

Recently, we reported a nitrate-bridged $\mathrm{Zn}_{6}^{\mathrm{II}} \mathrm{Dy}_{6}^{\mathrm{III}}$ dodecanuclear heterometallic cluster of Salen-like salicylamide ligand, 1(2-hydroxy-benzamido)-2-(2-hydroxy-benzylideneamino)ethane, which represents an unusual example of $\mathrm{Zn}^{\text {II }}-\mathrm{Dy}{ }^{\mathrm{III}}$ 


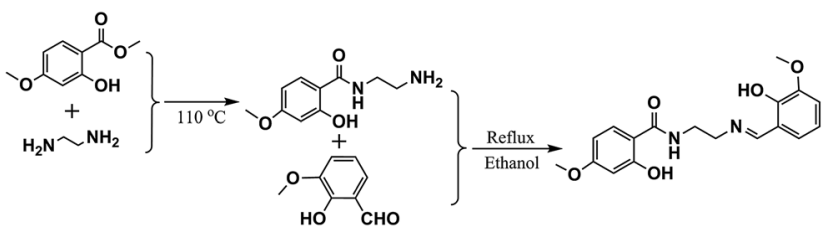

Scheme 1 The synthesis route of the ligand $\mathrm{H}_{3} \mathrm{~L}$.

cluster that exhibits ferromagnetic SMM behavior. ${ }^{10}$ However, the blocking temperature is lower than the temperature limit of the magnetometer even an external field of 2 kOe was applied. For the sake of increasing energy barrier and therefore to improve the SMM properties of $\mathrm{Zn}^{\mathrm{II}}$-Dy ${ }^{\text {III }}$ clusters of this kind of ligands, a new methoxy substituted Salen-like salicylamide ligand, 1-(2-hydroxy-4-methoxy-benzamido)-2-(2-hydroxy-3methoxy-benzylideneamino)-ethane $\left(\mathrm{H}_{3} \mathrm{~L}\right.$, Scheme 1$)$ was synthesised. The basis of the strategy presented herein, relies on the use of a new multidendate Salen-like salicylamide ligand as well as $o$-vanilline, which are elaborately selected to compartmentalize $\mathrm{Ln}^{\mathrm{III}}$ ions through oxygen based coordination pockets free of nitrate coordination. As a result, we succeeded in obtaining three heterometallic hexanuclear clusters, $\left[\mathrm{Zn}_{2} \operatorname{Ln}_{4}(-\right.$ $\left.\mathrm{HL})_{4}(o \text {-vanilline })_{2}(\mathrm{OH})_{4}\left(\mathrm{CH}_{3} \mathrm{OH}\right)_{2}\right] \cdot 2 \mathrm{NO}_{3} \cdot 5 \mathrm{CH}_{3} \mathrm{OH}(\mathrm{Ln}=\mathrm{Eu}, \mathrm{Tb}$ and Dy). The photophysical properties of compounds $\mathrm{Zn}_{2}^{\mathrm{II}} \mathrm{Eu}_{4}^{\mathrm{III}}, \mathrm{Zn}_{2}^{\mathrm{II}} \mathrm{Tb}_{4}^{\mathrm{III}}$ and $\mathrm{Zn}_{2}^{\mathrm{II}} \mathrm{Dy}_{4}^{\mathrm{III}}$ as well as the magnetic properties of $\mathrm{Zn}_{2}^{\mathrm{II}} \mathrm{Dy} y_{4}^{\mathrm{III}}$ have been explored and the results indicate $\mathrm{Zn}_{2}^{\mathrm{II}} \mathrm{Eu}_{4}^{\mathrm{III}}$ shows mixed emissions both originating from ligands and $\mathrm{Eu}^{\text {III }}$ ions, and the other two only display ligand-centered emission in visible region. Interestingly, the corresponding dysprosium containing complex $\mathrm{Zn}_{2}^{\mathrm{II}} \mathrm{Dy}_{4}^{\mathrm{III}}$ shows typical ferromagnetic single molecule magnetic behavior with slow zerofield relaxation. To our best knowledge, it is rather infrequent to observe ferromagnetic coupling and zero-field slow magnetic relaxation coexisted in $\mathrm{Zn}^{\mathrm{II}}-\mathrm{Ln}^{\mathrm{III}}$ heterometallic clusters.

\section{Experimental section}

\section{Materials}

Methyl 2-hydroxy-4-methoxybenzoate, ethane-1,2-diamine and 3-methoxy-4-hydroxybenzaldehyde were obtained from Aladain. Solvents and all other chemicals were analytical grade, available commercially, and used as received.

\section{Synthesis of the ligand}

1-(2-Hydroxy-4-methoxy-benzamido)-2-(2-hydroxy-3-methoxybenzylideneamino)-ethane $\left(\mathrm{H}_{3} \mathrm{~L}\right)$ is shown in Scheme 1. N-(2Aminoethyl)-2-hydroxy-4-methoxybenzamide was prepared according to literature using methyl 2-hydroxy-4-methoxybenzoate instead. ${ }^{11} 10 \mathrm{mmol}(1.52 \mathrm{~g}) o$-vanilline was added to a $30 \mathrm{~mL}$ ethanol solution of $N$-(2-aminoethyl)-2-hydroxy-4-methoxybenzamide $(2.10 \mathrm{~g}, 10 \mathrm{mmol})$ under stirring. The mixture was refluxed for $4 \mathrm{~h}$ to make a clear solution. Then the solution was rotary-evaporated to near dryness to obtain a pale-yellow solid. The yellow crystalline product obtained by ethanol recrystallization was washed with ethanol and dried in air. $\mathrm{H}_{3} \mathrm{~L}: 2.68 \mathrm{~g}$, yield
78.0\%. Mp 166-167 ${ }^{\circ}$ C. Analytical data, calc. for $\mathrm{C}_{18} \mathrm{H}_{20} \mathrm{~N}_{2} \mathrm{O}_{5}$ : C, 62.78; H, 5.85; N, 8.13; found: C, 62.81, H, 5.85, N, 8.17; IR (KBr, $\nu$, $\mathrm{cm}^{-1}$ ): 3393 (w), 2938 (w), 1649 (s), 1598 (s), 1544 (m), 1467 (m), $1389(\mathrm{~m}), 1251(\mathrm{~s}), 1204(\mathrm{~m}), 1160(\mathrm{~m}), 1076(\mathrm{~m}), 1022(\mathrm{~m}), 958$ (m), $831(\mathrm{~m}), 736(\mathrm{~m}) .{ }^{1} \mathrm{H}$ NMR $\left(\mathrm{CDCl}_{3}, 400 \mathrm{MHz}\right) \delta: 3.77(\mathrm{~m}, 3 \mathrm{H}$, $\left.\mathrm{CH}_{3}\right), 3.88\left(\mathrm{~m}, 3 \mathrm{H}, \mathrm{CH}_{3}\right), 3.80\left(\mathrm{~m}, 2 \mathrm{H}, \mathrm{CH}_{2}\right), 3.85\left(\mathrm{~m}, 2 \mathrm{H}, \mathrm{CH}_{2}\right)$, $6.71(\mathrm{~s}, 1 \mathrm{H}, \mathrm{ArH}), 6.80(\mathrm{~m}, 1 \mathrm{H}, \mathrm{ArH}), 6.88(\mathrm{~m}, 1 \mathrm{H}, \mathrm{ArH}), 6.97(\mathrm{~m}$, $1 \mathrm{H}, \mathrm{ArH}), 7.23(\mathrm{~m}, 1 \mathrm{H}, \mathrm{ArH}), 7.35(\mathrm{~m}, 3 \mathrm{H}, \mathrm{CH}=\mathrm{N}), 8.41(\mathrm{t}, 1 \mathrm{H}, \mathrm{NH}$, $J=4 \mathrm{~Hz}), 12.21(\mathrm{~s}, 2 \mathrm{H}, \mathrm{OH})$.

\section{Preparation of complexes}

General procedure. $27 \mu \mathrm{L}(0.2 \mathrm{mmol})$ triethylamine was added to a $15 \mathrm{~mL}$ acetonitrile solution containing $0.1 \mathrm{mmol}$ $(0.028 \mathrm{~g}) \mathrm{H}_{3} \mathrm{~L}$ and $0.1 \mathrm{mmol}(0.015 \mathrm{~g}) o$-vanilline. Then $0.1 \mathrm{mmol}$ $(0.021 \mathrm{~g}) \mathrm{Zn}\left(\mathrm{NO}_{3}\right)_{2} \cdot 2 \mathrm{H}_{2} \mathrm{O}$ was added and the solution was stirred for $4 \mathrm{~h}$ to obtain a suspension. $0.1 \mathrm{mmol} \mathrm{Ln}\left(\mathrm{NO}_{3}\right)_{3} \cdot 6 \mathrm{H}_{2} \mathrm{O}$ in 5 $\mathrm{mL}$ of methanol was added to this epinephelus solution and after another $4 \mathrm{~h}$ a clear solution was obtained. The mixture was stirred overnight and filtered into a sealed glass vial for crystallization at room temperature. After about three weeks pale yellow single crystals suitable for crystal analysis were obtained which were collected by filtration, washed with cold methanol, and dried in the air.

$\left[\mathrm{Zn}_{2} \mathrm{Eu}_{4}(\mathrm{HL})_{4}(\text { o-vanilline })_{2}(\mathrm{OH})_{4}\left(\mathrm{CH}_{3} \mathrm{OH}\right)_{2}\right] \cdot 2 \mathrm{NO}_{3} \cdot 5 \mathrm{CH}_{3} \mathrm{OH}$ $\left(\mathbf{Z n}_{2} \mathbf{E} \mathbf{E u}_{4}^{\text {III }}\right)$. The empirical formula and the molecular weight is $\mathrm{C}_{95} \mathrm{H}_{118} \mathrm{Eu}_{4} \mathrm{~N}_{10} \mathrm{O}_{43} \mathrm{Zn}_{2}$ and 2826.64 respectively. Yield: $36.7 \mathrm{mg}$, $52 \%$ based on $\mathrm{Eu}\left(\mathrm{NO}_{3}\right)_{3} \cdot 6 \mathrm{H}_{2} \mathrm{O}$. Analytical data (\%), calcd: C, 40.37; H, 4.21; N, 4.96; found: C, 40.22; H, 4.20; N, 4.98; IR (KBr, $\left.\nu, \mathrm{cm}^{-1}\right): 3456(\mathrm{w}), 1618(\mathrm{~s}), 1541(\mathrm{~s}), 1470(\mathrm{~s}), 1446(\mathrm{~s}), 1383(\mathrm{~m})$, $1217(\mathrm{~s}), 1168(\mathrm{~s}), 1130(\mathrm{~m}), 1074(\mathrm{~m}), 734(\mathrm{~m}), 594(\mathrm{~m})$.

$\left[\mathrm{Zn}_{2} \mathrm{~Tb}_{4}(\mathrm{HL})_{4}(o \text {-vanilline })_{2}(\mathrm{OH})_{4}\left(\mathrm{CH}_{3} \mathrm{OH}\right)_{2}\right] \cdot 2 \mathrm{NO}_{3} \cdot 5 \mathrm{CH}_{3} \mathrm{OH}$ $\left(\mathbf{Z n}_{\mathbf{2}}^{\mathrm{II}} \mathbf{T b}_{4} \mathbf{I I}\right)$. The empirical formula and the molecular weight is $\mathrm{C}_{95} \mathrm{H}_{118} \mathrm{~Tb}_{4} \mathrm{~N}_{10} \mathrm{O}_{43} \mathrm{Zn}_{2}$ and 2854.48 respectively. Yield: $34.2 \mathrm{mg}$, $48 \%$ based on $\mathrm{Tb}\left(\mathrm{NO}_{3}\right)_{3} \cdot 6 \mathrm{H}_{2} \mathrm{O}$. Analytical data (\%), calcd: C, 39.97; H, 4.17; N, 4.91; found: C, 40.16; H, 4.19; N, 4.94; IR (KBr, $\left.\nu, \mathrm{cm}^{-1}\right): 3435(\mathrm{w}), 1618(\mathrm{~s}), 1543(\mathrm{~s}), 1448(\mathrm{~s}), 1445(\mathrm{~s}), 1385(\mathrm{~m})$, $1217(\mathrm{~s}), 1168(\mathrm{~s}), 1130(\mathrm{~m}), 1074(\mathrm{~m}), 737(\mathrm{~m}), 592(\mathrm{~m})$.

$\left[\mathrm{Zn}_{2} \mathrm{Dy}_{4}(\mathrm{HL})_{4}(o \text {-vanilline })_{2}(\mathrm{OH})_{4}\left(\mathrm{CH}_{3} \mathrm{OH}\right)_{2}\right] \cdot 2 \mathrm{NO}_{3} \cdot 5 \mathrm{CH}_{3} \mathrm{OH}$ $\left(\mathbf{Z n}_{2}^{\text {II }} \mathbf{D y}_{2}\right.$ III). The empirical formula and the molecular weight is $\mathrm{C}_{95} \mathrm{H}_{118} \mathrm{Dy}_{4} \mathrm{~N}_{10} \mathrm{O}_{43} \mathrm{Zn}_{2}$ and 2868.68 respectively. Yield: $30.1 \mathrm{mg}$, $42 \%$ based on $\mathrm{Dy}\left(\mathrm{NO}_{3}\right)_{3} \cdot 6 \mathrm{H}_{2} \mathrm{O}$. Analytical data (\%), calcd: C, 39.77; H, 4.15; N, 4.88; found: C, 39.94; H, 4.13; N, 4.90. IR (KBr, $\left.\nu, \mathrm{cm}^{-1}\right): 3440(\mathrm{w}), 1618(\mathrm{~s}), 1544(\mathrm{~s}), 1470(\mathrm{~m}), 1446(\mathrm{~m}), 1386$ (m), 1211 (m), 1164 (m), 1130 (m), 1093 (m), 740 (m), 594 (m).

\section{Physical measurements}

Elemental analyses were performed on a Perkin-Elmer 2400 Series II CHNO elemental analyzer. IR spectra were recorded in the range $400-4000 \mathrm{~cm}^{-1}$ on a Perkin-Elmer FTIR spectrometer using $\mathrm{KBr}$ pellets. X-ray powder diffraction (XRPD) patterns of the samples were recorded on a X-ray diffractometer (Rigaku D/ Max 2200PC) with a graphite monochromator and $\mathrm{Cu} \mathrm{K} \alpha$ radiation $(\lambda=1.5418 \AA)$ at room temperature with a scan speed of $0.2 \mathrm{~s}$ per step and a step size of $0.02(2 \theta)$, while the voltage and electric current were held at $40 \mathrm{kV}$ and $20 \mathrm{~mA}$. Thermogravimetric analysis experiments were performed using a TGA/ 
NETZSCH STA449C instrument heated from $25-800{ }^{\circ} \mathrm{C}$ (heating rate of $10{ }^{\circ} \mathrm{C} \mathrm{min}^{-1}$, nitrogen stream). Emission and excitation spectra were recorded with a Hitachi F-7000 spectrophotometer equipped with quartz cuvettes of $2.5 \mathrm{~cm}$ path length. The luminescence decays were recorded using a pumped dye laser (Lambda Physics model FL2002) as the excitation source. The magnetic susceptibility measurements were obtained on a Quantum Design SQUID magnetometer MPMS-XL. Measurements were performed on a polycrystalline sample of $30.09 \mathrm{mg}$ for $\mathrm{Zn}_{2}^{\mathrm{II}} \mathrm{Dy} \mathrm{III}_{4}^{\mathrm{II}}$. Direct-current magnetic susceptibility measurements were carried out at $2-300 \mathrm{~K}$ for dc applied fields at 1000 Oe. Field dependence of the magnetization magnetic susceptibility measurements on the polycrystalline samples were performed with the same magnetometer. Alternating-current susceptibility measurements were carried out utilizing an oscillating ac field of 3.0 Oe and frequencies ranging from 20 to $1600 \mathrm{~Hz}$ under 0 and 2000 Oe dc field respectively. All crystalline samples for photoluminescence and magnetic studies were obtained from the same batch and characterized by PXRD, TG, EA and IR spectra.

\section{X-ray crystallography}

Suitable pale yellow block crystals of $\mathrm{Zn}_{2}^{\text {II }} \mathrm{Eu}_{4}^{\text {III }}(0.24 \times 0.18 \times$ $\left.0.14 \mathrm{~mm}^{3}\right), \mathrm{Zn}_{2}^{\mathrm{II}} \mathrm{Tb}_{4}^{\mathrm{III}}\left(0.32 \times 0.26 \times 0.14 \mathrm{~mm}^{3}\right)$ and $\mathrm{Zn}_{2}^{\mathrm{II}} \mathrm{Dy}_{4}^{\mathrm{III}}(0.33$ $\times 0.31 \times 0.23 \mathrm{~mm}^{3}$ ) were coated with perfluoropolyether oil before mounting. Intensity data of all the complexes were recorded at 293(2) K employing a Bruker SMART APEX II CCD diffractometer equipped with a monochromatized Mo $\mathrm{K} \alpha$ radiation $(\lambda=0.71073 \AA)$ source. No crystal decay was observed during the data collections. In all cases, absorption corrections based on multiscans using the SADABS software ${ }^{\mathbf{1 2}}$ were applied. The structures were solved by direct methods ${ }^{\mathbf{1 3}}$ and refined on $F^{2}$ by a full-matrix least-squares procedure. SHELXL was used for both structure solutions and refinements. ${ }^{\mathbf{1 4}}$ All nonhydrogen atoms were refined anisotropically. The positions of hydrogen atoms were calculated and isotropically fixed in the final refinement. The SMART and SAINT software packages ${ }^{15}$ were used for data collection and reduction respectively. Crystallographic diagrams were drawn using the DIAMOND software package. ${ }^{16}$ Also severely disordered methanol molecules in $\mathrm{Zn}_{2}^{\mathrm{II}} \mathrm{Eu}_{4}^{\mathrm{III}}, \mathrm{Zn}_{2}^{\mathrm{II}} \mathrm{Tb}_{4}^{\mathrm{III}}$ and $\mathrm{Zn}_{2}^{\mathrm{II}} \mathrm{Dy}_{4}^{\mathrm{III}}$ were removed by SQUEEZE during the structural refinements. ${ }^{17}$ For details about the squeezed material, see CIF data in ESI. $\uparrow$ Therefore, five methanol molecules which were determined on the basis of TGA and elemental microanalysis, and the data treated with the SQUEEZE routine within PLATON were added to the molecular formula of $\mathrm{Zn}_{2}^{\text {II }} \mathrm{Eu}_{4}^{\text {III }}, \mathrm{Zn}_{2}^{\text {II }} \mathrm{Tb}_{4}^{\text {III }}$ and $\mathrm{Zn}_{2}^{\text {II }} \mathrm{Dy}_{4}^{\text {III }}$ respectively.

\section{Result and discussion}

\section{Synthesis and characterization}

A stepwise synthetic protocol was employed to prepare the three heterometallic hexanuclear $\mathrm{Zn}^{\mathrm{II}}-\mathrm{Ln}^{\mathrm{III}}$ clusters. A suspension solution of zinc containing solution was obtained from the treatment of $\mathrm{Zn}\left(\mathrm{NO}_{3}\right)_{2} \cdot 2 \mathrm{H}_{2} \mathrm{O}$ with mixture of $\mathrm{H}_{3} \mathrm{~L}, o$-vanilline and triethylamine in $\mathrm{CH}_{3} \mathrm{CN}$ in a $1: 1: 2$ molar ratio. Addition of a solution of $\mathrm{Ln}\left(\mathrm{NO}_{3}\right)_{3} \cdot 6 \mathrm{H}_{2} \mathrm{O}$ in $\mathrm{MeOH}$ followed by magnetic stirring gave a clear pale yellow solution from which yellow crystals suitable for crystal analysis of $\mathrm{Zn}_{2}^{\mathrm{II}} \mathrm{Eu}_{4}^{\mathrm{III}}, \mathrm{Zn}_{2}^{\mathrm{II}} \mathrm{Tb}_{4}^{\mathrm{III}}$ and $\mathrm{Zn}_{2}^{\mathrm{II}} \mathrm{Dy}{ }_{4}^{\mathrm{II}}$ were obtained during the evaporation of the solvent after three weeks. The series of compounds were soluble in methanol, DMSO and DMF. Their chemical formulas were confirmed by elemental analysis. Consistent with the successful formation of the desired compounds, the characteristic bands of carbonyl and imine of the $\mathrm{H}_{3} \mathrm{~L}$ (1648 and $1598 \mathrm{~cm}^{-1}$ ) hypochromatic shifted about 30 and $49 \mathrm{~cm}^{-1}$, with two new bands presented at IR spectra $c a .1618 \mathrm{~cm}^{-1}$ and $1544 \mathrm{~cm}^{-1}$ respectively. The none but $\nu_{3}\left(1380 \mathrm{~cm}^{-1}\right)$ of the free nitrate groups' appearance in the IR spectra of the three compounds clearly indicates the exclusive existence of free nitrate groups as further confirmed by X-ray crystallography analysis as follows.

Thermal gravimetric analysis (TGA) were carried out under $\mathrm{N}_{2}$ atmosphere to show their thermal stability. As shown in Fig. $\mathrm{S} 1, \dagger$ the three hexanuclear complexes $\mathrm{Zn}_{2}^{\mathrm{II}} \mathrm{Eu}_{4}^{\mathrm{III}}, \mathrm{Zn}_{2}^{\mathrm{II}} \mathrm{Tb}_{4}^{\mathrm{III}}$ and $\mathrm{Zn}_{2}^{\mathrm{II}} \mathrm{Dy}{ }_{4}^{\mathrm{III}}$ showed very similar TG curves, and $\mathrm{Zn}_{2}^{\mathrm{II}} \mathrm{Dy}_{4}^{\mathrm{III}}$ is selected to describe as a representative. The thermal decomposition of $\mathrm{Zn}_{2}^{\mathrm{II}}$ $\mathrm{Dy}_{4}^{\mathrm{III}}$ occurs in a three-step process from 25 to $800{ }^{\circ} \mathrm{C}$. The first stage takes place in the range of $27-112{ }^{\circ} \mathrm{C}$ with a weight loss of $3.36 \%$ which was caused by the release of three crystalline methanol molecules free of hydrogen bonding. Upon further heating to about $168{ }^{\circ} \mathrm{C}$, the two crystalline hydrogen bonded nitrates and methanol molecules were lost and the weight loss was $6.54 \%$. Above $172{ }^{\circ} \mathrm{C}$, the entire architecture began to collapse. PXRD experiments were also carried out for $\mathrm{Zn}_{2}^{\mathrm{II}} \mathrm{Eu}_{4}^{\mathrm{III}}, \mathrm{Zn}_{2}^{\mathrm{II}} \mathrm{Tb}_{4}^{\mathrm{III}}$ and $\mathrm{Zn}_{2}^{\mathrm{II}} \mathrm{Dy}_{4}^{\mathrm{III}}$ to verify whether the crystal structures are truly representative of the bulk materials. As we can see in Fig. S2, $\uparrow$ the experimental patterns are in good agreement with that of the simulated ones indicating the as-synthesized samples are pure enough for spectroscopic and magnetic properties' study.

\section{Description of structures}

Signal-crystal X-ray diffraction analysis revealed that the assynthesized $\mathrm{Zn}^{\mathrm{II}}-\mathrm{Ln}^{\mathrm{III}}$ clusters are all sandwich-type hexanuclear compounds with a formula of $\left[\mathrm{Zn}_{2} \mathrm{Ln}_{4}(\mathrm{HL})_{4}(o \text {-vanilline })_{2}(\mathrm{OH})_{4}(-\right.$ $\left.\left.\mathrm{CH}_{3} \mathrm{OH}\right)_{2}\right] \cdot 2 \mathrm{NO}_{3} \cdot 5 \mathrm{CH}_{3} \mathrm{OH}$. For they are isostructural, here we select $\mathrm{Zn}_{2}^{\mathrm{II}} \mathrm{Dy}_{4}^{\mathrm{III}}$ to describe their structure features in detail. The crystal structure of $\mathrm{Zn}_{2}^{\mathrm{II}} \mathrm{Dy}_{4}^{\mathrm{III}}$ consists of a divalent cationic entity $\left[\mathrm{Zn}_{2} \mathrm{Dy}_{4}(\mathrm{HL})_{4}(\mathrm{o} \text {-vanilline })_{2}(\mathrm{OH})_{4}\left(\mathrm{CH}_{3} \mathrm{OH}\right)_{2}\right]^{2+}$, two uncoordinated nitrate anions for charge balance, and five crystalline methanol molecules. A cursory glance at the structure reveals that a $\mu_{3}-\mathrm{OH}^{-}$bridged $\mathrm{Dy}_{4}^{\mathrm{III}}$ core is sandwiched between two layers composed of one $\mathrm{Zn}^{\mathrm{II}}$, two $\mathrm{HL}^{2-}$ and one deprotonated $o$-vanilline (Fig. 1a) with the asymmetric unit shows half of the molecule. As depicted in Fig. 1b, Zn1 is in an tetragonal pyramidal geometry coordinated by two phenolate oxygen atoms from two different $\mathrm{HL}^{2-}$ ligands, one oxygen atom from $\mu_{3}$-hydroxyl group, and two imine nitrogen atoms from two different $\mathrm{HL}^{2-}$ ligands. Meanwhile, two crystallographically independent Dy ${ }^{\text {III }}$ ions (Dy1 and Dy2) are merely coordinated to eight oxygen atoms with Dy-O bond lengths range between 2.189 and $2.645 \AA$ A. Exact geometry analysis by SHAPE 2.1 software shows that the inner coordination sphere of eight- 


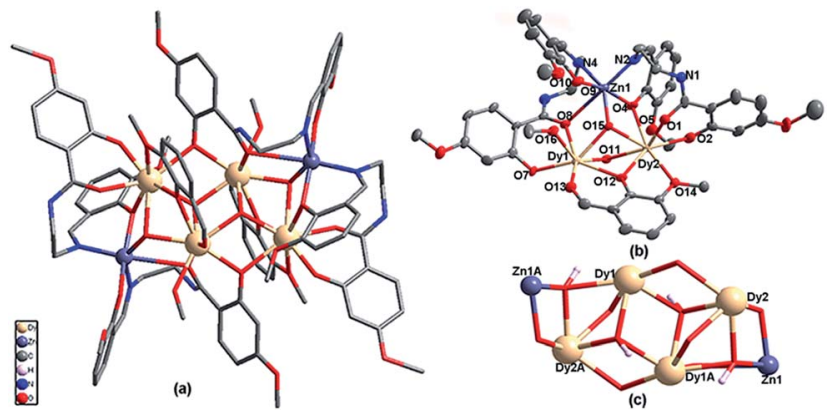

Fig. 1 (a) Structure of the cation $\left[\mathrm{Zn}_{2} \mathrm{Dy}_{4}(\mathrm{HL})_{4}(\mathrm{O} \text {-vanilline })_{2}(\mathrm{OH})_{4}(-\right.$ $\left.\left.\mathrm{CH}_{3} \mathrm{OH}\right)_{2}\right]^{2+}$ in $\mathrm{Zn}_{2}^{\prime \prime} \mathrm{Dy} y_{4}^{\prime \prime \prime}$ (b) asymmetric unit with atomic labels in $\mathrm{Zn}_{2}^{\prime \prime D y} y_{4}^{\mathrm{III}}(\mathrm{H}$ atoms as well as crystalline nitrate anion and methanol molecules are omitted for clarity); (c) the phenoxy/hydroxo-bridged metal framework $\left[\mathrm{Zn}_{2} \mathrm{Dy}_{4} \mathrm{O}_{8}\right]$ in $\mathrm{Zn}_{2}^{\prime \prime} \mathrm{Dy}{ }_{4}^{\prime \prime \prime}$.

coordinated Dy ${ }^{\text {III }}$ ions are residing in distorted biaugmented trigonal prisms with a deviation of 6.174 for Dy1 and 8.035 for Dy2 from the ideal $C_{2 \mathrm{v}}$ symmetry (Fig. S3†). ${ }^{9 k, 18}$ Owing to the two oxygen atoms from two hydroxyl groups (O11 and O15) and one phenoxo oxygen atom (O12) of singly deprotonated $o$-vanilline, Dy1 and Dy2 are bridged to give a trigonal pyramid $\left[\mathrm{Dy}_{2} \mathrm{O}_{3}\right]$ unit. Furthermore, $\mathrm{Zn} 1$ is appended at Dy2 site with two oxygen bridge ( $\mathrm{O} 4$ and $\mathrm{O} 15)$

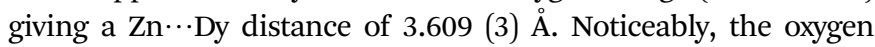
atoms both from two hydroxyl groups (O11) and four phenoxo oxygen atom of doubly deprotonated $\mathrm{HL}^{2-}$ anion $(\mathrm{O} 7)$ and singly deprotonated $o$-vanilline $(\mathrm{O} 12)$ further bridged the crystallographically Dy1 and Dy2 forming two plane-sharing cubic units $\left[\mathrm{Dy}_{4} \mathrm{O}_{6}\right]$ short of one vertex (Fig. 1c). The Dy $\cdots$ Dy distances of the four precisely coplanar Dy ${ }^{\text {III }}$ ions are 3.567(7) $\AA$ and 3.889(5) $\AA$. Such tetranuclear subunits with four $\mu_{3}-\mathrm{OH}^{-}$displaced above and below the Dy 4 plane by 0.869(2) $\AA$ and 0.490(4) $\AA$ can be viewed as a parallelogram and the shortest edge, Dy $1 \cdots$ Dy2A, is that which comprises three oxygen bridges. Noticeably, this structural characteristic is quite different from reported $\mathrm{OH}^{-}$bridged $\mathrm{Dy}_{4}$ clusters. ${ }^{19}$

\section{Luminescent properties}

Chromogenic $\mathrm{Zn}^{\mathrm{II}}$ components have been used as sensitizers for lanthanide luminescence following ligand $\rightarrow \mathrm{f}$ and $\mathrm{d} \rightarrow \mathrm{f}$ energy-transfers. ${ }^{20}$ The photophysical properties of $\mathrm{H}_{3} \mathrm{~L}, o$ vanilline, $\mathrm{Zn}_{2}^{\mathrm{II}} \mathrm{Eu}_{4}^{\mathrm{III}}, \mathrm{Zn}_{2}^{\mathrm{II}} \mathrm{Tb}_{4}^{\mathrm{III}}$ and $\mathrm{Zn}_{2}^{\mathrm{II}} \mathrm{Dy} y_{4}^{\mathrm{III}}$ in solid state were studied and their emission spectra is shown in Fig. 2.

Upon UV irradiation at $340 \mathrm{~nm}$, both $\mathrm{H}_{3} \mathrm{~L}$ and $o$-vanilline present very broad bands ranging from $435 \mathrm{~nm}$ to $600 \mathrm{~nm}$, which could be attributed to $\pi^{*} \rightarrow \pi$ and intramolecular charge transitions of $\mathrm{H}_{3} \mathrm{~L}$ and $o$-vanilline. The excitation spectra of $\mathrm{Zn}_{2}^{\mathrm{II}} \mathrm{Eu}_{4}^{\mathrm{III}}$ exhibits broad bands ranging from $325 \mathrm{~nm}$ to $425 \mathrm{~nm}$ upon $\mathrm{Eu}^{\mathrm{III}}$-centered emission (Fig. S4†). Excited at $c a .365 \mathrm{~nm}$, $\mathrm{Zn}_{2}^{\mathrm{II}} \mathrm{Eu}_{4}^{\mathrm{III}}$ shows reddish luminescence and exhibits both ligandcentered $\left(\lambda_{\max }=456 \mathrm{~nm}\right)$ and the typical $\mathrm{f} \rightarrow \mathrm{f}$ transitions of the $\mathrm{Eu}^{\text {III }}$ ion with the former stronger than the latter. As for the characteristic emission of $\mathrm{Eu}^{\mathrm{III}}$ ion, the strong emission peak at 599 and $621 \mathrm{~nm}$ is assigned to magnetic dipolar ${ }^{5} \mathrm{D}_{0} \rightarrow{ }^{7} \mathrm{~F}_{1}$ transition and the electric dipolar ${ }^{5} \mathrm{D}_{0} \rightarrow{ }^{7} \mathrm{~F}_{2}$ transition respectively, the weak one at $582 \mathrm{~nm}$ can be attributed to the ${ }^{5} \mathrm{D}_{0}$

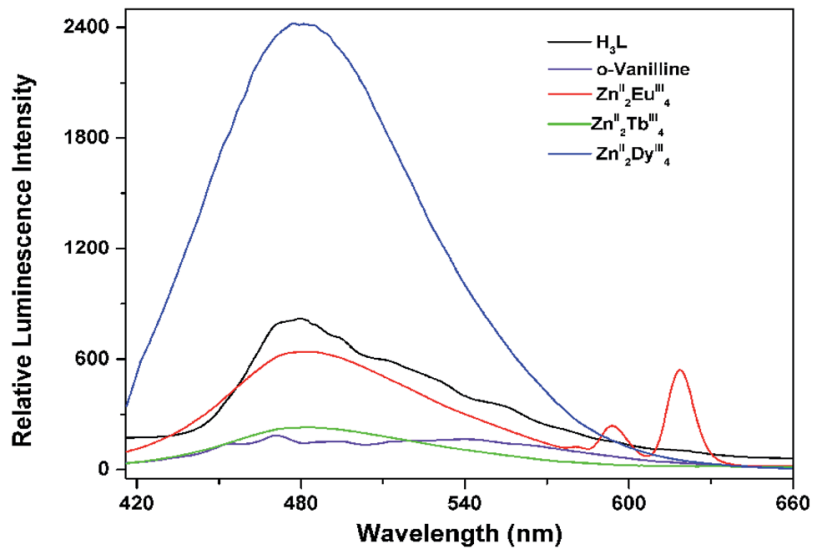

Fig. 2 Emission spectra of $\mathrm{H}_{3} \mathrm{~L}, \mathrm{O}$-vanilline, $\mathrm{Zn} \mathrm{n}_{2}^{\prime \prime} E u_{4}^{\prime \prime \prime}, \mathrm{Zn}_{2}^{\prime \prime} T b_{4}^{\prime \prime \prime}$ and $\mathrm{Zn}_{2}^{\prime \prime} \mathrm{Dy}_{4}^{\prime \prime \prime}$ in solid state (excitation and emission passes $=2.5 \mathrm{~nm}$ ).

$\rightarrow{ }^{7} \mathrm{~F}_{0}$ transition. The intensity of the ${ }^{5} \mathrm{D}_{0} \rightarrow{ }^{7} \mathrm{~F}_{2}$ transition is about 2.26 times stronger than that of the ${ }^{5} \mathrm{D}_{0} \rightarrow{ }^{7} \mathrm{~F}_{1}$ transitions, higher than the value (0.67) for a centrosymmetric $\mathrm{Eu}^{\mathrm{III}}$ compound. ${ }^{21}$ The symmetry-forbidden emission ${ }^{5} \mathrm{D}_{0} \rightarrow{ }^{7} \mathrm{~F}_{0}$ also appears in the emission spectra of $\mathrm{Zn}_{2}^{\mathrm{II}} \mathrm{Eu}_{4}^{\mathrm{III}}$. All these indicate that $\mathrm{Eu}^{\text {III }}$ ions in $\mathrm{Zn}_{2}^{\text {II }} \mathrm{Eu}_{4}^{\text {III }}$ occupy sites with low symmetry and have no inversion center which is in good agreement with the result of the single crystal structure analyses. The luminescence decay of $\mathrm{Zn}_{2}^{\mathrm{II}} \mathrm{Eu}_{4}^{\mathrm{III}}$ is best described by a double-exponential process with significantly shorter lifetimes of $\tau_{1}=0.245 \mathrm{~ms}$, $\tau_{2}=0.072 \mathrm{~ms}$ observed likely because of the presence of two distinct emitting species (Fig. S5†). When the same system were adopted to populate the excited state of the $\mathrm{Tb}^{\mathrm{III}}$ ion, the ligands-centered emission rather than $\mathrm{Tb}^{\mathrm{III}}$ luminescence is observed, indicating this mixed system can transfer some excitation energy to $\mathrm{Eu}^{\mathrm{III}}$ than to $\mathrm{Tb}^{\mathrm{III}}$ ions. Compared to that of $\mathrm{Zn}_{2}^{\mathrm{II}} \mathrm{Eu}_{4}^{\mathrm{III}}$, the luminescence lifetime of $\mathrm{Zn}_{2}^{\mathrm{II}} \mathrm{Tb}_{4}^{\text {III }}$ is quite shorter with $\tau=0.097 \mathrm{~ms}$ (Fig. S6 $\dagger$ ). In the case of $\mathrm{Zn}_{2}^{\mathrm{II}} \mathrm{Dy}_{4}^{\mathrm{III}}$, very strong blue emission with shortest lifetime of $9 \mathrm{~ns}$ (Fig. S7 $\dagger$ ) attributed to $\mathrm{Zn}$-ligands system presented. It is well-known that the presence of $\mathrm{OH}$ oscillators in the lanthanide first coordination sphere provides an efficient non-radiative path, ${ }^{22}$ so we can suggest that the observed weak $\mathrm{Eu}^{\mathrm{III}}$ luminescence in $\mathrm{Zn}_{2}^{\mathrm{II}} \mathrm{Eu}_{4}^{\mathrm{III}}$ and the absence of $\mathrm{Tb}^{\mathrm{III}} / \mathrm{Dy}^{\mathrm{III}}$-centered emission are mainly related to increases in non-radiative transitions due to the presence of $\mathrm{OH}$ oscillators in the first coordination shell together with the mismatch between resonance energy levels of $\mathrm{Ln}^{\mathrm{III}}$ and excited states of ligands in these clusters. Notably, the emission spectra of the three clusters showed negligible changes when excited at different wavelengths as shown in Fig. S8-S10. $\dagger$

\section{Magnetic properties}

The static magnetic behaviour of the $\mathrm{Zn}_{2}^{\mathrm{II}} \mathrm{Dy}_{4}^{\mathrm{III}}$ complex through direct current (dc) magnetic measurements between 2 and 300 $\mathrm{K}$ with an applied dc field of 1000 Oe was performed on microcrystalline samples. As observed in Fig. $3 \mathrm{a}$, the $\chi_{\mathrm{M}} T$ value almost remains unchanged from 300 to $12 \mathrm{~K}$ with a value of $57.44 \mathrm{~cm}^{3} \mathrm{~K} \mathrm{~mol}^{-1}$ at $300 \mathrm{~K}$ which is fairly close to the expected 

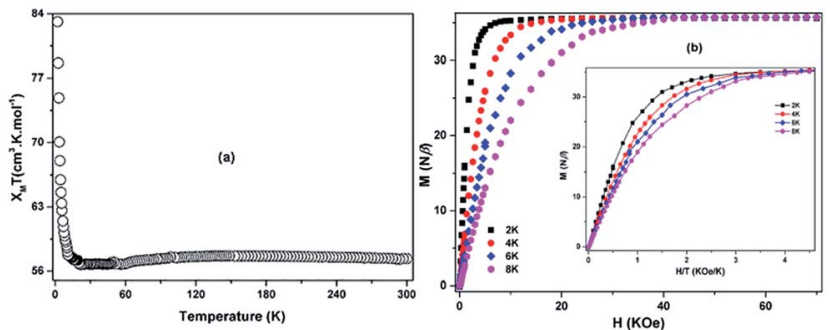

Fig. 3 (a) Temperature dependence of $\chi_{M} T$ for $Z n_{2}^{\| D} D y_{4}^{\prime \prime \prime}$ at $1000 \mathrm{Oe}$ over the temperature of $2-300 \mathrm{~K}$; (b) M vs. $H$ plots and $M$ vs. $H T^{-1}$ plots (inset) for $\mathrm{Zn}_{2}^{\prime \prime} \mathrm{Dy} y_{4}^{\prime \prime \prime}$ at different temperatures.

value of $56.68 \mathrm{~cm}^{3} \mathrm{~K} \mathrm{~mol}^{-1}$ for four uncoupled Dy ${ }^{\mathrm{III}}$ ions $\left({ }^{6} \mathrm{H}_{15 / 2}\right.$, $g=4 / 3)$. Below $10 \mathrm{~K}$, the $\chi_{\mathrm{M}} T$ value sharply goes up upon cooling and reaches $83.11 \mathrm{~cm}^{3} \mathrm{~K} \mathrm{~mol}^{-1}$ at $2 \mathrm{~K}$. This behavior indicates that spin-orbital coupling leads the $4 \mathrm{f}^{n}$ configuration of $\mathrm{Ln}^{\text {III }}$ to split into ${ }^{2 S+1} \mathrm{~L}_{J}$ states, and further into Stark components under the crystal-field perturbation, and the effect of depopulation of the Stark components of $\mathrm{Dy}^{\mathrm{III}}$ is nearly equal of the ferromagnetic coupling between Dy ${ }^{\mathrm{III}}$ ions in the higher temperature range. The increase of $\chi_{\mathrm{M}} T$ in the low-temperature range obviously implies the presence of ferromagnetic coupling between ${ }^{D y}{ }^{\text {III }}$ ions, and it is strong enough to overcome the effect of depopulation of the Stark components of Dy ${ }^{\mathrm{III}} .{ }^{8}$ Such strong ferromagnetic interactions are rare for both $\mathrm{Zn}^{\mathrm{II}}-\mathrm{Ln}^{\mathrm{III}}$ clusters and $\mathrm{Ln}^{\mathrm{III}}$ complexes. ${ }^{23}$ Its occurrence may result from the connecting of two $\left[\mathrm{Dy}_{2} \mathrm{Zn}\right]$ building blocks through two $\mu_{3}-\mathrm{OH}^{-}$. bridge. In $\mathrm{Zn}_{2}^{\mathrm{II}} \mathrm{Dy} 4$, the $\left[\mathrm{Dy}_{4} \mathrm{O}_{6}\right]$ core was closely wrapped and the Dy- $\mathrm{OH}^{-}$-Dy angles with shortest distance of $3.567(7) \AA$ are 96.51 and $98.76^{\circ}$, which therefore may lead to the strong uniaxial anisotropy of the Dy ${ }^{\mathrm{III}}$ ion..$^{23 d}$ By comparison, a similar $\mathrm{Dy}_{4}$ clusters with the $\mathrm{Dy}-\mathrm{OH}^{-}$-Dy angle above $103.95^{\circ}$ exhibits antiferromagnetic interactions. ${ }^{19 a}$ The $M v s . H$ data below $8 \mathrm{~K}$ show a rapid increase in the magnetization at low magnetic fields (Fig. 2b) which is expected for materials having ferromagnetically coupled spins. at higher fields, $M$ increases slowly reaching a value of $36 \mu_{\mathrm{B}}$ which almost close to the theoretical value of $40 \mu_{\mathrm{B}}$ of four Dy ${ }^{\mathrm{III}}$ ions. The nonsuperposition of $M v s$. $H T^{-1}$ in different fields (Fig. 2b inset) suggests the presence of significant magnetic anisotropy and/or low-lying excited states in $\mathrm{Zn}_{2}^{\mathrm{II}} \mathrm{Dy}_{4}^{\mathrm{III}}$.

In addition, it is worth mentioning that the $M v s . H$ data do not exhibit a hysteresis effect above $2 \mathrm{~K}$ with sweep rates used (100-300 Oe $\left.\mathrm{min}^{-1}\right)$. The absence of the $M v$ v. $H$ hysteresis loop at $2 \mathrm{~K}$ may be caused by the presence of a relatively fast zerofield relaxation as ascertained as follows. ${ }^{24}$

To further explore the dynamics of magnetization, we performed alternating current (ac) magnetic measurements on $\mathrm{Zn}_{2}^{\mathrm{II}} \mathrm{Dy}{ }_{4}^{\mathrm{III}}$. Expectedly, strong frequency dependences for the real $\chi_{M^{\prime}}{ }^{-T}$ and the imaginary $\chi^{\prime \prime}{ }_{M}-T$ parts of the ac susceptibilities were observed below $20 \mathrm{~K}$ as shown in Fig. 4. In plots of both $\chi_{M^{-}}{ }^{-T}$ and $\chi^{\prime \prime}{ }_{M^{-}}-T$, the peaks are observed above $20 \mathrm{~Hz}$ and shift to high temperature with increasing frequencies, which is the nature of slow magnetic relaxation. Noticeably, both $\chi_{M}^{\prime}$ and $\chi_{M}^{\prime \prime}$ below about $6 \mathrm{~K}$ increase with decreasing temperature,
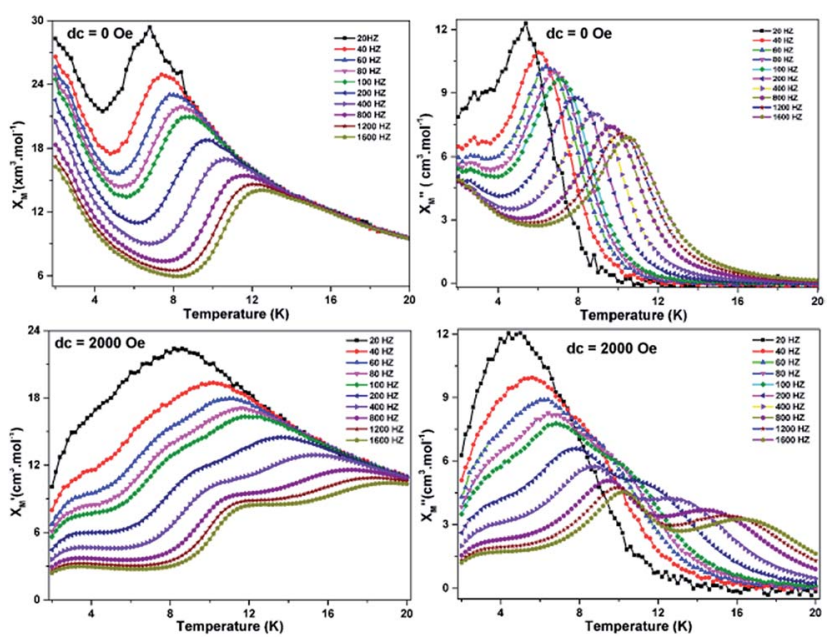

Fig. 4 Ac magnetic measurements for $\mathrm{Zn}_{2} \mathrm{DDy}_{4}^{\prime \prime \prime}$ at $H_{\mathrm{ac}}=3 \mathrm{Oe}$ and $H_{\mathrm{dc}}=0 \mathrm{Oe} / 2000$ Oe respectively.

indicating the intervention of QTM. For Kramer's ions, such as Dy ${ }^{\mathrm{III}}$, dipole-dipole and hyperfine interactions allow the mixing of the two Kramer's ground states at zero field, leading to the quantum tunnelling dynamics of the magnetization. Therefore, the temperature and frequency dependent ac susceptibility were measured under an applied 2000 Oe field which is also shown in Fig. 4. The diminishing of the upward $\chi_{{ }_{M}}$ and $\chi^{\prime \prime}{ }_{M}$ at low temperatures can be taken as a clear indication of the efficient suppression of zero-field tunneling of magnetization occurring in $\mathrm{Zn}_{2}^{\mathrm{II}} \mathrm{Dy}_{4}^{\mathrm{III}}$. In addition, compared with magnetization at zero-field, the out-of-phase component $\chi^{\prime \prime}{ }_{M}$ for higher frequencies exhibits a series of frequency-dependent peaks around $16.5 \mathrm{~K}$, with a second set around $6 \mathrm{~K}$, which indicates two relaxation processes dominate for $\mathrm{Zn}_{2}{ }^{\mathrm{II}} \mathrm{Dy}_{4}{ }^{\mathrm{III}}$ under an applied 2 kOe field. The low temperature one (RLT) and high temperature one (RHT) could be ascribed to the two different Dy ${ }^{\mathrm{II}}$ ions centers in $\mathrm{Zn}_{2}^{\mathrm{II}} \mathrm{Dy}_{4}^{\mathrm{III}} \cdot{ }^{25}$

Soncini et al. used an electrostatic model to determine the magnetic anisotropy in dysprosium complexes and their results indicated the ground state of $\mathrm{Dy}^{\mathrm{III}}$ is doublet quantized along the anisotropy axis with an angular momentum quantum number $m_{J}= \pm 15 / 2$ in absence of high symmetry. ${ }^{26}$ Theoretical research has presented that the large magnetic anisotropy is obtained when only the low-lying ground state, $| \pm 15 / 2\rangle$ Kramers doublet, is significantly populated. ${ }^{27}$ In case of $\mathrm{Zn}_{2}^{\mathrm{II}} \mathrm{Dy}{ }_{4}^{\mathrm{III}}$, the combination of long and short Dy-O bond length in the ligand field can facilitate the stability of the oblate shape of $| \pm 15 / 2\rangle$ Kramers doublet, which in turn leads to strong magnetic anisotropy. ${ }^{29}$ The peak temperatures, $T_{\mathrm{p}}$, obtained by the Lorentzian peak function fitting from plots of $\chi^{\prime \prime}{ }_{\mathrm{M}^{-}}-T$ deduce a linear plot of $1 / T_{\mathrm{p}} v s . \ln (2 \pi f)$ and obey the Arrhénius law $1 / T_{\mathrm{p}}$ $=-k_{\mathrm{B}} / \Delta E\left[\ln (2 \pi f)+\ln \tau_{0}\right]$ (Fig. 5), where $f$ is the frequency. The best fitting of out-of-phase component $\chi^{\prime \prime}{ }_{\mathrm{M}}$ under zero dc field yields the energy barrier $\Delta E / k_{\mathrm{B}}=56.7 \mathrm{~K}$ and the relaxation time $\tau_{0}=4.8 \times 10^{-7} \mathrm{~s}$, which are comparable to those of reported Dy ${ }^{\text {III }}$-based SMMS. ${ }^{28}$

Plotting the relaxation time $\tau$ of out-of-phase component $\chi^{\prime \prime}{ }_{M}$ under 2000 Oe dc field versus the temperature $T_{\mathrm{p}}{ }^{-1}$ and a linear 


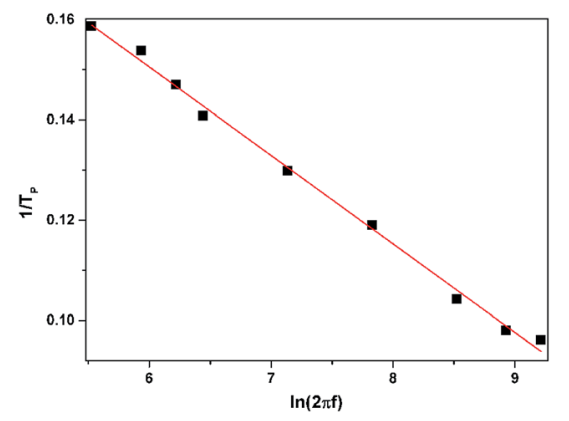

Fig. 5 The least-squares fit of the experimental data at $H_{\mathrm{dc}}=0$ Oe to the Arrhenius equation.

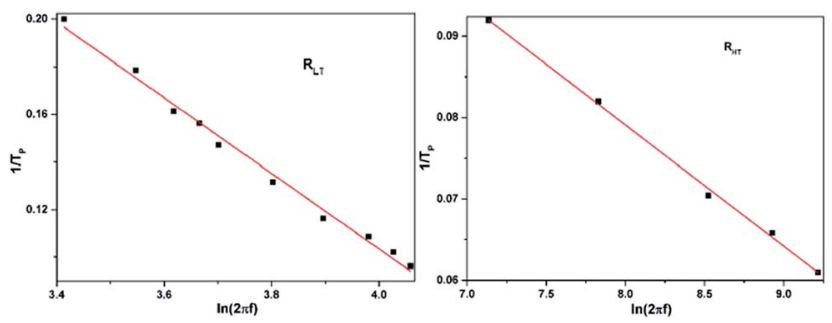

Fig. 6 The least-squares fit of the experimental data at $H_{\mathrm{dc}}=2000 \mathrm{Oe}$ to the Arrhenius equation.
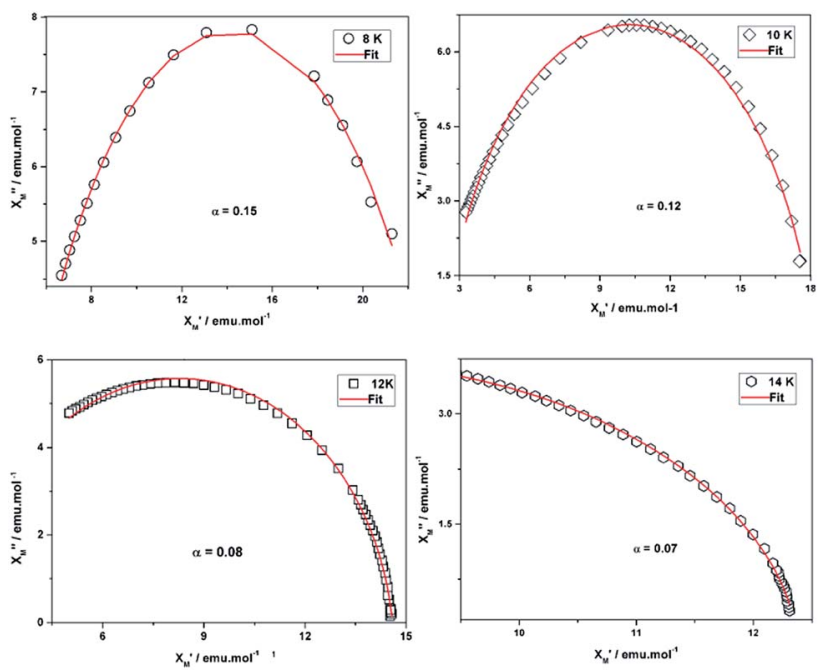

Fig. 7 Plots of $\chi_{M}^{\prime \prime}$ Vs. $\chi_{M}^{\prime}$ of $Z_{2} \mathrm{Dy}_{4}$ at $8 \mathrm{~K}(O), 10 \mathrm{~K}(\diamond), 12 \mathrm{~K}(\square)$ and $14 \mathrm{~K}(\square)$ respectively. Red solid lines are the least-squares fitting results to a distribution of single relaxation processes with the small $\alpha$ value.

fitting of the thermally activated points to the Arrhenius law afford $\Delta E_{1} / k_{\mathrm{B}}=6.30 \mathrm{~K}$ and the relaxation time $\tau_{1}=9.55 \times$ $10^{-3} \mathrm{~s}$ for RLT and $\Delta E_{2} / k_{\mathrm{B}}=67.1 \mathrm{~K}$ and $\tau_{2}=1.66 \times 10^{-6} \mathrm{~s}$ for RHT (Fig. 6). As a comparison, the energy barriers extracted from the high temperature regions is only a slight increase of the energy barrier, indicating that the quantum tunneling effect in this compound is not very pronounced. ${ }^{29}$

The frequency dependence of ac susceptibilities at zero field leads to the semicircle Cole-Cole plots of $\chi^{\prime \prime}{ }_{M} v s . \chi^{\prime}{ }_{M}$ (Fig. 7) at
8, 10, 12 and $14 \mathrm{~K}$, respectively. The least-squares fitting results of the data are in good agreement with a distribution of single relaxation processes with $\alpha$ parameters of $0.07-0.15(\alpha=0$ corresponding to an infinitely narrow distribution of relaxation times), which is also compatible with the value reported. ${ }^{30}$ The shift of the peak temperature $\left(T_{\mathrm{p}}\right)$ of $\chi^{\prime \prime}{ }_{\mathrm{M}}$ is measured by a parameter $\phi=\left(\Delta T_{\mathrm{p}} / T_{\mathrm{p}}\right) / \Delta(\log f)=0.26$, which falls in the range of a normal value for a superparamagnet. ${ }^{8}$

\section{Conclusions}

The self-assembly of a methoxy substituted salicylamide Salenlike ligand and $o$-vanilline in $\mathrm{Zn}^{\mathrm{II}}-\mathrm{Ln}^{\mathrm{III}}$ chemistry led to three sandwich-like heterometallic clusters with hydroxyl bridged tetranuclear $\mathrm{Ln}_{4}^{\mathrm{III}}$ core swaddled by $\mathrm{Zn}^{\mathrm{II}}$ ion and deprotonated ligands. Photophysical determination indicate that $\mathrm{Zn}_{2}^{\mathrm{II}} \mathrm{Eu}_{4}^{\mathrm{III}}$ shows mixed emission both originating from ligands and $\mathrm{Eu}^{\mathrm{III}}$ ions, and ligand-centered emission in visible region is exclusively found for $\mathrm{Zn}_{2}^{\mathrm{II}} \mathrm{Tb}_{4}^{\mathrm{III}}$ and $\mathrm{Zn}_{2}^{\mathrm{II}} \mathrm{Dy}_{4}^{\mathrm{III}}$. Interestingly, $\mathrm{Zn}_{2}^{\mathrm{II}} \mathrm{Dy}{ }_{4}^{\mathrm{III}}$ exhibits strong ferromagnetic magnetic behavior with a slow zero-field relaxation with $\tau_{0}=4.8 \times 10^{-7} \mathrm{~s}$ and $\Delta E / k_{\mathrm{B}}=$ $56.7 \mathrm{~K}$. To our best knowledge, it is quite unusual that strong ferromagnetic coupling and slow magnetic relaxation coexist in $\mathrm{Zn}^{\text {II }}-\mathrm{Ln}^{\mathrm{III}}$ heterometallic clusters. Our current studies on construction of high-nuclearity heterometallic clusters are helpful in achieving further insights into the rational design and preparation of novel multifunctional $\mathrm{Zn}^{\mathrm{II}}-\mathrm{Ln}^{\mathrm{III}}$ heterometallic clusters. Further studies focused on the construction of $\mathrm{d}-\mathrm{f}$ nanoclusters of Salen-like salicylamide ligands with other auxiliary ligands, different substitution and different d-metal ions are in progress in our group.

\section{Acknowledgements}

This work was supported by the National Natural Science Foundation of China (Grant: 21661019) and Gansu Natural Science Foundation of China. (Grant: 1212RJZA038).

\section{Notes and references}

1 (a) M. Brewer, J. Lee and J. G. Brennan, Inorg. Chem., 1995, 34, 5919; (b) M. Berardini, T. J. Emge and J. G. Brennan, Inorg. Chem., 1995, 34, 5327; (c) J. Ruiz, G. Lorusso, M. Evangelisti, E. K. Brechin, S. J. A. Pope and E. Colacio, Inorg. Chem., 2014, 53, 3586; (d) T. D. Pasatoiu, C. Tiseanu, A. M. Madalan, B. Jurca, C. Duhayon, J. P. Sutter and M. Andruh, Inorg. Chem., 2011, 50, 5879.

2 K. Z. Su, F. L. Jiang, J. J. Qian, M. Y. Wu, K. C. Xiong, Y. L. Gai and M. C. Hong, Inorg. Chem., 2013, 52, 3780.

3 H.-B. Xu, H.-M. Wen, Z.-H. Chen, J. Li, L.-X. Shi and Z.-N. Chen, Dalton Trans., 2010, 39, 1948.

4 X.-Q. Lü, W.-X. Feng, Y.-N. Hui, T. Wei, J.-R. Song, S.-S. Zhao, W.-Y. Wong, W.-K. Wong and R. A. Jones, Eur. J. Inorg. Chem., 2010, 2010, 2714.

5 Z.-S. Meng, F.-S. Guo, J.-L. Liu, J.-D. Leng and M.-L. Tong, Dalton Trans., 2012, 41, 2320. 
6 X. P. Yang, Z. P. Li, S. Q. Wang, S. M. Huang, D. Schipperc and R. A. Jones, Chem. Commun., 2014, 50, 15569.

7 L. Zhang, L. Zhao, P. Zhang, C. Wang, S.-W. Yuan and J. K. Tang, Inorg. Chem., 2015, 54, 11535.

8 Z. Chen, B. Zhao, P. Cheng, X.-Q. Zhao, W. Shi and Y. Song, Inorg. Chem., 2009, 48, 3493.

9 (a) H. Zhang, G.-L. Zhuang, X.-J. Kong, Y.-P. Ren, L.-S. Long, R.-B. Huang and L.-S. Zheng, Cryst. Growth Des., 2013, 13, 2493; (b) R. Modak, Y. Sikdar, G. Cosquer, S. Hatterjee, M. Yamashita and S. Goswami, Inorg. Chem., 2016, 55, 691; (c) S. Osa, T. Kido, N. Matsumoto, N. Re, A. Pochaba and J. Mrozinski, J. Am. Chem. Soc., 2004, 126, 420; (d) S. F. Xue, Y.-N. Guo, L. Zhao, H. X. Zhang and J. K. Tang, Inorg. Chem., 2014, 53, 8165; (e) I. A. Kühne, G. E. Kostakis, C. E. Anson and A. K. Powell, Inorg. Chem., 2016, 55, 4072; (f) J. Q. Zhang, C. Li, J. J. Wang, M. Zhu and L. C. Li, Eur. J. Inorg. Chem., 2016, 2016, 1383; $(g)$ X. F. Wang, P. Hu and J.-P. Sutter, Inorg. Chem., 2015, 54, 9664; (h) H.-R. Wen, J. Bao, S.-J. Liu, C. M. Liu, C.-W. Zhang and Y.-Z. Tang, Dalton Trans., 2015, 44, 11191; (i) W.-W. Kuang, L. L. Zhu, L. C. Li and P.-P. Yang, Eur. J. Inorg. Chem., 2015, 2015, 2245; (j) Y.-A. Liu, C.-Y. Wang, M. Zhang and X.-Q. Song, Polyhedron, 2017, 127, 278; (k) F. J. Kettles, V. A. Milway, F. Una, R. Valiente, L. H. Thomas, W. Wernsdorfer, S. T. Ochsenbein and M. Murrie, Inorg. Chem., 2014, 53, 8970.

10 X.-Q. Song, P.-P. Liu, Y.-A. Liu, J.-J. Zhou and X. L. Wang, Dalton Trans., 2016, 45, 8154.

11 X.-Q. Song, P.-P. Liu, Z.-R. Xiao, X. Li and Y.-A. Liu, Inorg. Chim. Acta, 2015, 438, 232.

12 D. C. Santra, K. B. Manas, K. S. Pradip and M. Sudip, Chem.Eur. J., 2016, 22, 2012.

13 G. M. Sheldrick, Acta Crystallogr., Sect. A: Found. Crystallogr., 1990, 46, 467.

14 G. M. Sheldrick, SHELXL-2014, University of Gottingen, Gottingen, Germany, 2014.

15 (a) SAINT, version 6.02, Bruker AXS Inc, Madison, WI, 2002; (b) K. Bhattacharya, M. Maity, D. Mondal, A. Endo and M. Chaudhury, Inorg. Chem., 2012, 51, 7454.

16 (a) DIAMOND, Visual Crystal Structure Information System, version 3.1, Crystal Impact, Bonn, Germany, 2004; (b) X.-Q. Song, Y.-K. Lei, X.-R. Wang, M.-M. Zhao, Y.-Q. Peng and G.-Q. Cheng, J. Solid State Chem., 2014, 218, 202.
17 A. L. Spek, J. Appl. Crystallogr., 2003, 36, 7.

18 A. K. Mondal, H. S. Jena, A. Malviya and S. Konar, Inorg. Chem., 2016, 55, 5237.

19 (a) P.-H. Guo, J.-L. Liu, Z.-M. Zhang, L. Ungur, L. F. Chibotaru, J. D. Leng, F.-S. Guo and M.-L. Tong, Inorg. Chem., 2012, 51, 1233; (b) H. S. Ke, P. Gamez, L. Zhao, G.-F. Xu, S. F. Xue and J. K. Tang, Inorg. Chem., 2010, 49, 7549.

20 X. P. Yang, D. Schipper, R. A. Jones, L. A. Lytwak, B. J. Holliday and S. M. Huang, J. Am. Chem. Soc., 2013, 135, 8468.

21 M. Latva, H. Takalo, V.-M. Mukkala, C. Matachescu, J. C. Rodríguez-Ubis and J. Kankare, J. Lumin., 1997, 75, 149. 22 (a) W. D. Horrocks Jr, J. Am. Chem. Soc., 1979, 101, 334; (b) X. Q. Song, X. Y. Zhou, W. S. Liu, W. Dou, J. X. Ma, X. L. Tang and J. R. Zheng, Inorg. Chem., 2008, 47, 11501.

23 (a) M. Chen, E. C. Sañudo, E. Jiménez, S.-M. Fang, C.-S. Liu and M. Du, Inorg. Chem., 2014, 53, 6708; (b) R.-X. Yao, X. Xu and X.-M. Zhang, RSC Adv., 2014, 4, 53954; (c) S.-J. Liu, J.-P. Zhao, W.-C. Song, S.-D. Han, Z.-Y. Liu and X.-H. Bu, Inorg. Chem., 2013, 52, 2103; (d) P. Zhang, L. Zhang, S.-Y. Lin and J. K. Tang, Inorg. Chem., 2013, 52, 6595.

24 P.-H. Lin, T. J. Burchell, R. Clérac and M. Murugesu, Angew. Chem., Int. Ed., 2008, 47, 8848.

25 W.-B. Sun, B. Yan, L.-H. Jia, B.-W. Wang, Q. Yang, X. Cheng, H.-F. Li, P. Chen, Z.-M. Wang and S. Gao, Dalton Trans., 2016, 45, 8790.

26 N. F. Chilton, D. Collison, E. J. L. McInnes, R. E. P. Winpenny and A. Soncini, Nat. Commun., 2013, 4, 2551.

27 I. Oyarzabal, J. Ruiz, J. M. Eco, M. Evangelisti, A. Camón, E. Ruiz, D. Aravena and E. Colacio, Chem.-Eur. J., 2014, 20, 14262.

28 S. Liu, K. Lang, Y. Zhang, Q. Yang, B. Wang and S. A Gao, Dalton Trans., 2016, 45, 8149.

29 G. Abbas, Y. Lan, G. E. Kostakis, W. Wernsdorfer, C. E. Anson and A. K. Powell, Inorg. Chem., 2010, 49, 8067.

30 (a) W.-M. Wang, W.-Z. Qiao, H.-X. Zhang, S.-Y. Wang, Y.-Y. Nie, H.-M. Chen, Z. Liu, H.-L. Gao, J.-Z. Cui and B. Zhao, Dalton Trans., 2016, 45, 8182; (b) G. Xiong, X. Y. Qin, P. F. Shi, Y. L. Hou, J. Z. Cui and B. Zhao, Chem. Commun., 2014, 50, 4255; (c) R. Modak, Y. Sikdar, G. Cosquer, S. Chatterjee, M. Yamashita and S. Goswami, Inorg. Chem., 2016, 55, 691. 